\section{SCORECARD}

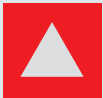

San Francisco's offices Mayor Gavin Newsom has banned bottled water for thirsty city workers who will now be offered only environmentally friendly water from the tap.

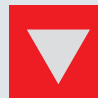

TV remote controls Even the humble remote might soon feel too

much like hard work. Japanese firm Hitachi has unveiled a 'brain interface' that it hopes will ultimately allow users to change channels just by thinking about it.

\section{ON THE RECORD}

\section{"The conservation of the bald eagle is a true reflection of the concern Americans have for the environment."}

George Fenwick, president of the American Bird Conservancy, is pleased by the news that the nation's emblem is to be removed from the Endangered Species Act's list of threatened species.

\section{c(It's the same as you feel after a plate of spaghetti.》”}

Alessandro Sannino, Italian researcher and inventor of the 'fill pill', explains how his invention, which is made out of the same absorbent material as nappies, helps dieters by expanding to take up space in the stomach.

\section{OVERHYPED}

\section{The iPhone}

Yes it's beautiful. Yes it's multifunctional. But ultimately it's only a telephone, and therefore not worth camping out for days on end to get your hands on.

Sources: Reuters, Fox News, American Bird

Conservancy,

Daily Mirror,

Associated

Press

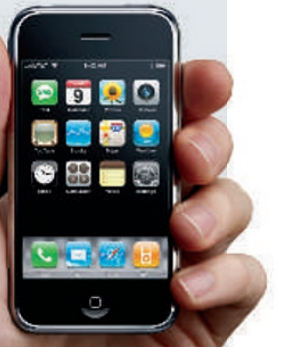

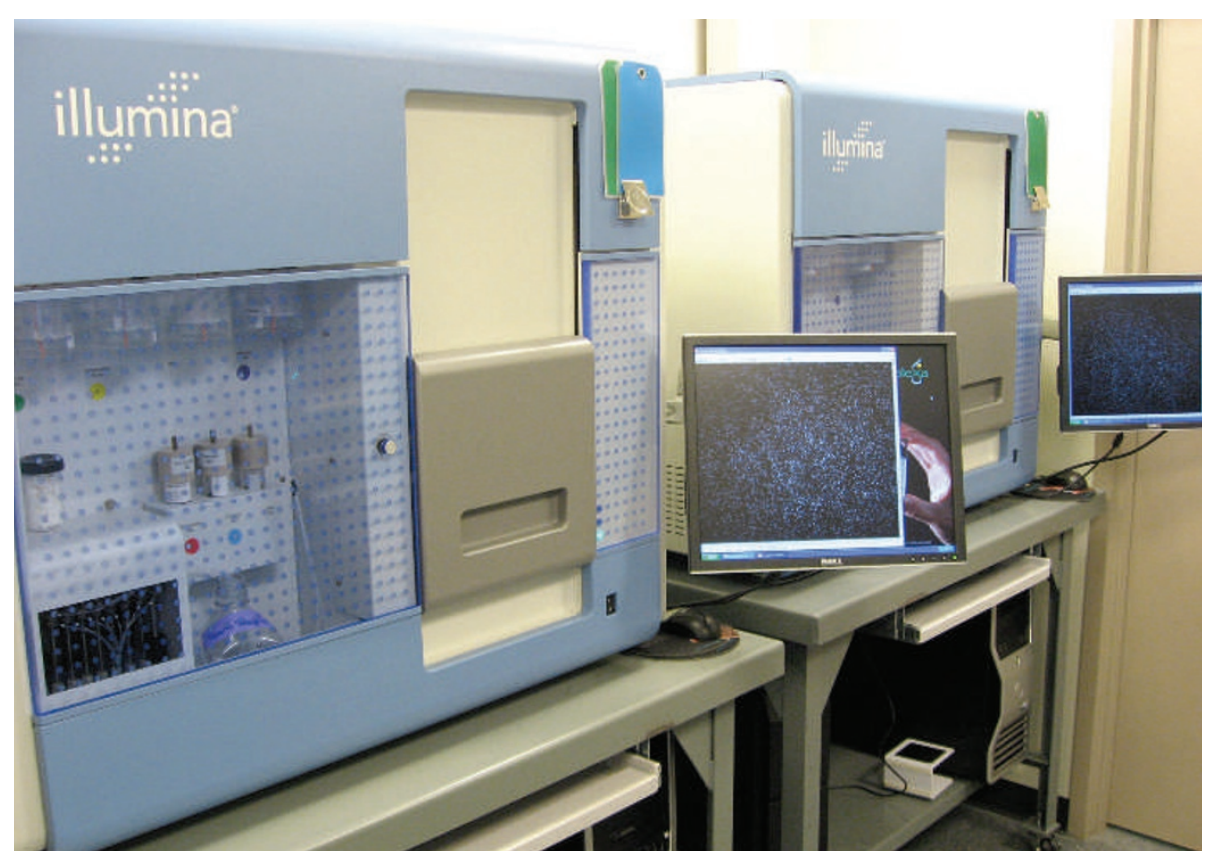

Sequencing machines such as the $1 \mathrm{G}$ are revolutionizing the speed at which DNA is analysed.

\title{
Faster still and faster
}

A new generation of sequencing machines is broadening horizons for users. Various groups have recently performed epigenetic studies - looking at modifications to the genome that control its expression - that would have been utterly impractical using old technologies.

The latest approach fishes out all the DNA associated with a given marker, such as one of the histone proteins used to package genes in chromosomes. Then, instead of comparing each piece of DNA with a library of previously isolated sequences, as used to be done, scientists simply sequence the whole lot.

The key to this approach is new technology such as that sold by Solexa, a company that earlier this year merged with Illumina of San Diego. "The amount of DNA sequence being produced by these machines is staggering," says Steven Jones, associate director of the Genome Sciences Centre at the British Columbia Cancer Agency in Vancouver. Working flat out, a Solexa $1 \mathrm{G}$ machine could triple the total amount of DNA sequence contained in the GenBank database in just one year.

Jones's group looked at histone changes that control which regions of DNA can be read ${ }^{1}$. Meanwhile, scientists from the Broad Institute in Cambridge, Massachusetts, and Massachusetts General Hospital in Boston used a Solexa machine to examine two types of histone modification in mouse cells. Their paper ${ }^{2}$, published online in Nature on 1 July, describes how these modifications change during development, and how such changes can either keep cells poised to switch fates, or close down their future options.

"The excitement about this paper is that we now have a means of studying cellular state in a high-throughout manner," says Bradley Bernstein, a pathologist at Massachusetts General Hospital who co-led the work with Broad director Eric Lander. "We certainly couldn't have done this on a genome-wide scale before." (See 'Sequencing revolution ushers in new era.)

This advance is already unveiling new biology, says Keji Zhao of the US National Heart, Lung and Blood Institute in Bethesda, Maryland. Zhao's group has used it to decipher the messages encoded by two types of epigenetic mark produced by adding methyl groups to $\mathrm{DNA}^{3}$. Zhao says scientists' ability to take largescale, complete snapshots means it might one day be possible to catalogue all the non-genetic alterations that control how genes are expressed in various cells and at all stages of development. And progress could be breakneck: Zhao's group took delivery of its first Solexa machine in January and published its results in May.

Beyond epigenetics, says Lander, other ambitious projects beckon. For example, this May, the genome of genomics pioneer James Watson was bared to the world ${ }^{4}$ after being sequenced using technology from 454 Life Sciences, a company based in Branford, Connecticut, that has 